\title{
Подход к повышению эффективности производственного процесса с использованием объемных композитных структур
}

\author{
() В. И. Румянцева, В. В. Виноградов
}

Национальный исследовательский университет ИТМО

Россия, 197101 г. Санкт-Петербург, проспект Кронверкский, 49.

\section{Email: valeriya_rumyantceva@scamt-itmo.ru}

В качестве подхода к повышению эффективности производственного процесса предложена объемная печать композитных структур, содержащих энтрапированные клетки микроорганизмов, с контролируемыми свойствами сборки и функцией многократного разложения пищевых отходов.

Ключевые слова: ферментные системы, наноструктурированные композиты, объемные структуры, контролируемые параметры, пищевая биотехнология, ресурсосбережение.

В настоящее время все большую актуальность приобретает проблема неэффективного способа утилизации пищевых отходов, содержащих питательные компоненты. Так, например, при многотоннажном изготовлении хлеба и хлебных продуктов в переработку уходит не более $10 \%$ неиспользованной продукции [8]. При этом большинство из них являются пригодными для разложения и получения нового вида производственного сырья, но нуждаются в прохождении специальных процессов подготовки и обработки. Вариант внедрения фрерментативной конструкции многократного использования представлен на рисунке 1.

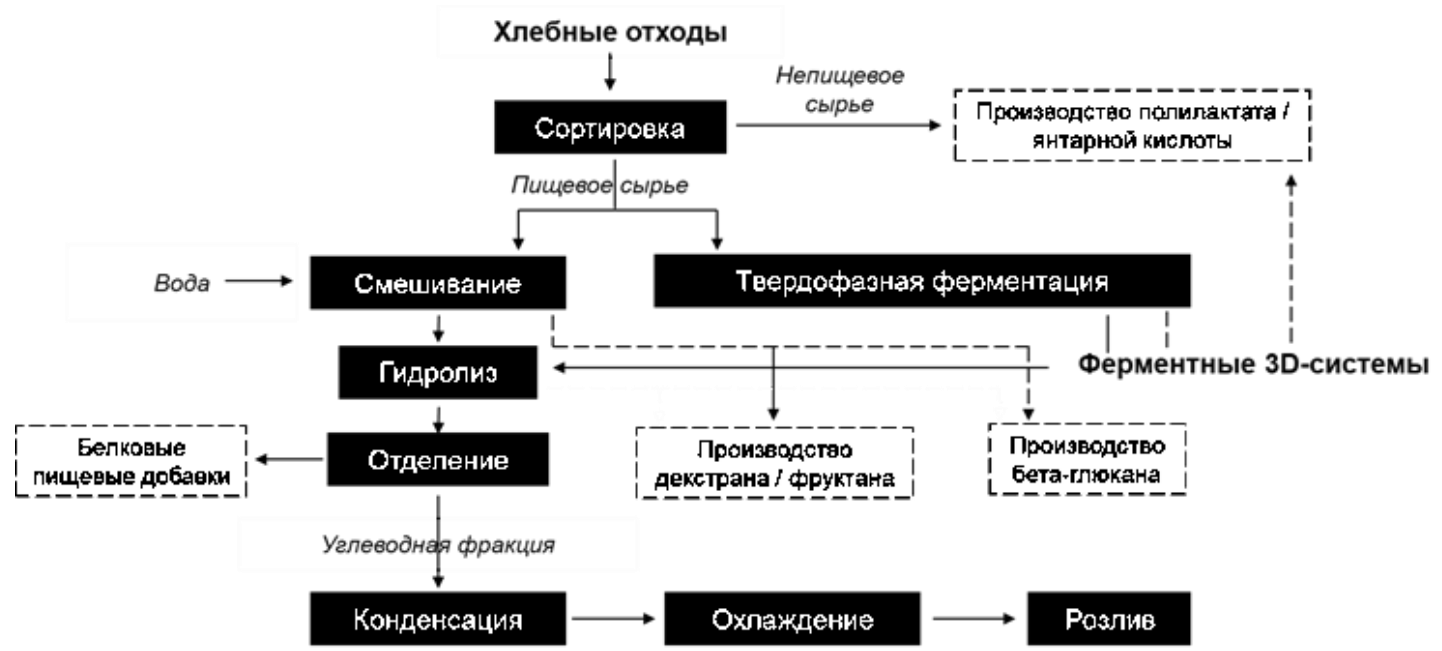

Рис. 1. Схема переработки вторичного хлебного сырья с помощью ферментных 3D систем. 
В изготовлении многих функциональных продуктов используются процессы фрерментации. Это позволяет получать продукт с минимальным количеством синтетических соединений, применяемых в производственном цикле и различных процессах очистки конечного субстрата. Однако непрерывный процесс обновления ферментативного субстрата с его последующей иммобилизацией приводит к тому, что технология становится экономически нецелесообразной для массовой доступности товара.

На сегодняшний день существует несколько разработок для повышения эффективности использования ферментативного процесса на производстве. Так, например, используется реактивация агрегированных белков или необратимо денатурированных фрерментов [1], десорбция фермента со стенок реакционного сосуда [2]. Однако они не способны удовлетворить всем требованиям доступности, эффрективности и безопасности. Кроме того, для выделения фрерментативных комплексов из их источника необходимо использовать ряд специально подобранных технологий, в том числе по обработке и подготовке к использованию, иммобилизацию и т.п. [5]. Одним из вариантов является химическое осаждение для прикрепленных к бактериальной клетке катализирующих соединений. Данный метод позволяет выделить одновременно целый комплекс фрерментов, например, целлюлозосому из бактерий рода Clostridium [5]. Для использования таких комплексов в пищевом производстве необходимо соблюдать требования по безопасности их использования: фильтрацию, холодную стерилизацию и т.п.

В то же время, в современном мире большую популярность по решению многих производственных проблем приобретают аддитивные технологии [12-13,15]. Предполагается, что создание «живых» фрерментных каркасных структур, ориентированных на повышение эфрфективности и, в то же время, экологичность производства, позволит преодолеть трудности, связанные с нестабильностью фрермента, продолжительностью его действия и многократностью использования. Возможность управления процессом ферментации позволит получать целевой продукт с заданной совокупностью свойств. Направленное действие системы обеспечивает оптимальные условие ее применения [10-11]. Экструзионная объемная печать способна решить ряд проблем, связанных с дозированием отдельных структур общей системы и направлением их сборки. Также установлено, что данные методы сборки способствуют стабильному послойному фрормированию структур [3].

Исследованиями установлено, что важную роль в объемной печати играет полимерный материал, из которого изготавливаются конструкции. Соотношение компонентов и природа полимера сказывается на эффрективности работы всей системы. При этом большую популярность приобретают естественные полимерные соединения, такие как фрибриллярный белок [4,6], целлюлоза и наноцеллюлоза [9], желатин [4], пектин [14].

В данной работе исследован потенциал использования аддитивной технологии формирования многокомпонентных 3D-структур с энтрапированием модельного организма - дрожжей.

В качестве перспективной технологии была использована печать с отверждением ближним ультрафиолетовым излучением, посредством которого возможно получить продукт с низкой степенью контаминации и высокой степенью выживаемости целевых клеток дрожжей [9].

Был осуществлен синтез матрицы для биочернил: золь наноцеллюлозы двух видов (NCNC и S-CNC), связующий (диметакрилат полиэтиленгликоля) и сшивающий (фенил2,4,6-триметилбензоилфосфинат лития) компоненты и культура микроорганизмов в виде дрожжевого субстрата. Структуры были напечатаны в виде кубовидной решетки, в качестве контроля использовали плотную структуру с формой висячей капли. 
На основании литературных данных и анализа вязкости компонентов биочернил было подобрано их наиболее оптимальное соотношение 90:10:9 в пользу содержания наноцеллюлозы $[7,8]$. Содержание дрожжевых клеток определялось соотношением по массе 10:1 относительно наноцеллюлозы.

Основная целесообразность использования системы определялась на основании эффективного получения конечного продукта. Во избежание контаминации рабочей среды содержание этанола в растворе определяли в процентах по массе. Массу рабочей системы определяли в несколько этапов (табл. 1).

Таблица 1. Определение массы рабочей системы

\begin{tabular}{|c|c|c|c|c|c|c|}
\hline \multirow[t]{3}{*}{ Образец } & \multicolumn{6}{|c|}{ Этапы измерения массы, г } \\
\hline & \multirow{2}{*}{$\begin{array}{c}\text { Масса с } \\
\text { дрожжами }\end{array}$} & \multirow{2}{*}{$\begin{array}{c}\text { Первый } \\
\text { этап } \\
\text { (48 ч) }\end{array}$} & \multicolumn{2}{|c|}{ Второй этап (48 ч) } & \multicolumn{2}{|c|}{ Третий этап (48 ч) } \\
\hline & & & исходное & $\begin{array}{c}\text { с заменой } \\
\text { среды }\end{array}$ & исходное & $\begin{array}{c}\text { с заменой } \\
\text { среды }\end{array}$ \\
\hline Контроль & $5,019 \pm 0,005$ & $4,969 \pm 0,007$ & $4,958 \pm 0,004$ & - & $4,947 \pm 0,002$ & - \\
\hline $\begin{array}{l}\text { N-CNC } \\
\text { куб1 }\end{array}$ & $5,517 \pm 0,009$ & $5,479 \pm 0,008$ & - & $5,471 \pm 0,007$ & - & $5,476 \pm 0,007$ \\
\hline $\begin{array}{l}\mathrm{N}-\mathrm{CNC} \\
\text { куб2 }\end{array}$ & $5,518 \pm 0,003$ & $5,472 \pm 0,009$ & $5,463 \pm 0,009$ & - & $5,459 \pm 0,009$ & - \\
\hline $\begin{array}{l}\text { N-CNC } \\
\text { шаp1 }\end{array}$ & $5,513 \pm 0,007$ & $5,490 \pm 0,006$ & - & $5,493 \pm 0,004$ & - & $5,499 \pm 0,004$ \\
\hline $\begin{array}{l}\mathrm{N}-\mathrm{CNC} \\
\text { шар2 }\end{array}$ & $5,518 \pm 0,007$ & $5,493 \pm 0,009$ & $5,487 \pm 0,007$ & - & $5,481 \pm 0,007$ & - \\
\hline
\end{tabular}

Результаты продемонстрировали необходимость замены среды каждые 48 ч для обновления питательных компонентов в системе и способствования постадийной пролифрерации дрожжевых клеток. Динамику выделения спирта из глюкозосодержащей среды определяли во временном интервале от 48 до 240 ч (рис. 2). 


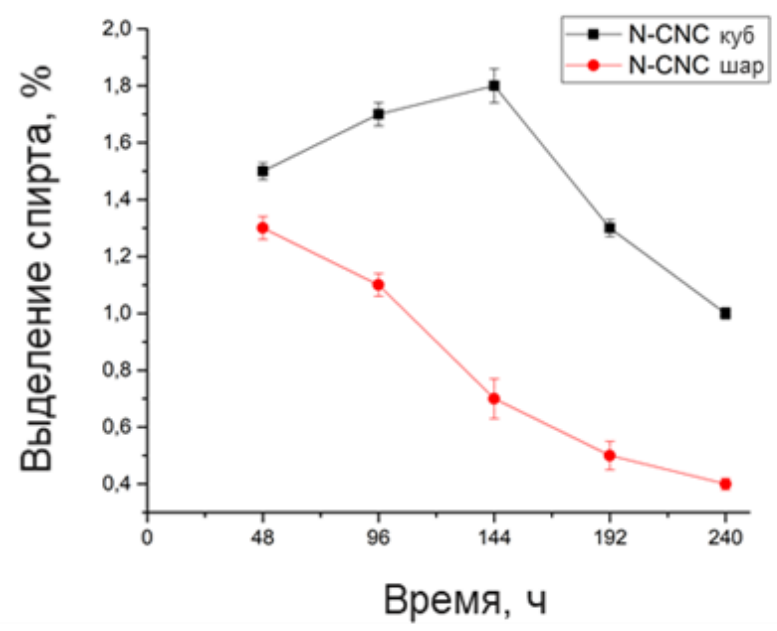

Рис. 2. Динамика выделения этилового спирта из глюкозосодержащего субстрата.

На основании калибровочной кривой эталона этанола и с учетом перерасчета на массу рабочего раствора вычислили, что разработанные структуры способны перерабатывать глюкозосодержащую среду до этилового спирта в количестве около 1,5 \% в среднем в течение пяти этапов использования. Для шарообразных структур данный показатель ниже, и при этом он не сохраняется на дальнейших этапах использования. С течением времени до 144 часов система претерпевает незначительные изменения, в том числе связанные со стабильностью структурно-механических свойств объемной структуры, однако переработка оставшегося субстрата продолжает осуществляться.

Работа выполнена при в рамках НИР №390434 «Синтез и применение наноструктурированных чернил для 3D печати материалов широкого спектра применения».

\section{Литература}

1. Brown I. et al. Kinetic study of the thermal denaturation of a hyperthermostable extracellular $\alpha$-amylase from Pyrococcus furiosus // Biochimica et Biophysica Acta (BBA)-Proteins and Proteomics. - 2013. - T. 1834. - №. 12. - C. 2600-2605. - 1

2. De Lathouder K. M. et al. Structured reactors for enzyme immobilization: a monolithic stirrer reac-tor for application in organic media // Chemical Engineering Research and Design. - 2006. - T. 84. - №. 5. - C. 390-398. - 2

3. González-Henríquez C. M., Sarabia-Vallejos M. A., Rodríguez Hernandez J. Antimicrobial polymers for additive manufacturing // International journal of molecular sciences. 2019. - T. 20. - №. 5. - C. 1210. - 3

4. Huang L. et al. Bacterial cellulose nanofibers promote stress and fidelity of 3D-printed silk based hydrogel scaffold with hierarchical pores // Carbohydrate Polymers. - 2019. - T. 221. - № December 2018. - C. 146-156.

5. Hyeon J. E., Shin S. K., Han S. O. Design of nanoscale enzyme complexes based on various scaffolding materials for biomass conversion and immobilization // Biotechnology Journal. - 2016. - T. 11. - № 11. - C. 1386-1396. - 4

6. Kiseleva A.P. et. al. Optically active hybrid materials based on natural spider silk // ACS Applied Materials and Interfaces. - 2019. - T. 11. - № 26. - C. 22962-22972. 
7. McCarthy R. R. et al. The use of bacterial polysaccharides in bioprinting //Biotechnology advances. - 2019. - T. 37. - №. 8. - C. 107448. - 6

8. Melikoglu M., Webb C. Use of Waste Bread to Produce Fermentation Products: Mehmet Melikoglu, Colin Webb // Food Industry Wastes. - 2013. - C. 63-76. - 7

9. Qian F. et al. Direct Writing of Tunable Living Inks for Bioprocess Intensification // Nano Letters. - 2019. - T. 19. - № 9. - C. 5829-5835. - 8

10. Rumyantceva V. I. et al. Biocide-conjugated magnetite nanoparticles as an advanced platform for biofilm treatment//Therapeutic Delivery, IET. - 2019. - T. 10. - № 4. - C. 241250. -9

11. Rumyantceva V. I. et. al. Magnetically controlled carbonate nanocomposite with ciprofloxacin for biofilms eradication // International Journal of Molecular Sciences. - 2021. T. 22. - C. $6187 .-10$

12. Schaffner M. et al. 3D printing of bacteria into functional complex materials // Science Advances. - 2017. - T. 3. - № 12. - C. eaao6804. - 11

13. Shavandi A., Jalalvandi E. Biofabrication of bacterial constructs: New threedimensional biomaterials // Bioengineering. - 2019. - T. 6. - № 2. - C. 1-6. - 12

14. Vancauwenberghe V. et al. 3D printing of plant tissue for innovative food manufacturing: Encapsulation of alive plant cells into pectin based bio-ink // Journal of Food Engineering. - 2019. - T. 263. - C. 454-464

15. Xiang $\mathrm{H}$. et al. UV-curable, 3D printable and biocompatible silicone elastomers // Progress in Organic Coatings. - 2019. - T. 137. - C. 105372. -13

\title{
An approach to improving the efficiency of the production process using volumetric composite structures
}

\author{
V. I. Rumyantceva, V. V. Vinogradov \\ ITMO University \\ 49-A Kronverkskiy prospect, 197101 Saint-Petersburg, Russia.
}

Email: valeriya_rumyantceva@scamt-itmo.ru

As an approach to improving the efficiency of the production process, the volume printing of composite structures containing entrapped cells of microorganisms with controlled assembly properties and the function of multiple decomposition of food waste is proposed.

Keywords: enzyme systems, nanostructured composites, bulk structures, controlled parameters, food biotechnology, resource conservation. 